\title{
Implementation and evaluation of a mental health nursing residency program
}

\author{
Barb Pizzingrilli , Derek Christensen \\ Mental Health and Addictions Program, Niagara Health System, St Catharines, Canada
}

Received: September 24, 2014

Accepted: October 22, $2014 \quad$ Online Published: October 30, 2014

DOI: $10.5430 /$ jnep.v5n1p76

URL: http://dx.doi.org/10.5430/jnep.v5n1p76

\begin{abstract}
Objective: The Niagara Health System opened a new healthcare facility in 2013 with expansion of the Mental Health and Addictions Program. As part of operational readiness planning, the decision was made to implement a 12-week residency program to support a cohort of ten new nursing staff in attaining the knowledge, confidence, and recovery attitudes required for practice. This paper will detail the planning and implementation of a Mental Health Nursing Residency Program at the Niagara Health System. The outcomes of the residency program will be discussed as well as the challenges that will inform recommendations for future programming. There is a paucity of literature related to mental health specific residency programs, and this paper will add to the work that has already been done in this specialty area of practice.

Methods: Ten nurses new to mental health participated in the 12-week residency program. The program was evaluated using pre and post measures of knowledge, confidence, and recovery attitudes at the beginning and end of the residency program. Retention rates were also examined for the cohort of new staff. Results were obtained from eight of the ten participants for data analysis. Descriptive statistics were used to describe the sample, recovery attitudes, and retention. Knowledge and confidence data were analyzed using paired $t$-tests.
\end{abstract}

Results: Statistically significant improvements occurred in knowledge and confidence. Recovery attitudes also improved but retention of staff who participated in the residency program was not enhanced.

Conclusions: A residency program can be an effective strategy to ensure that nurses new to the field of mental health and addictions have the requisite competencies for practice.

Key Words: Mental health, Residency program, Nursing, Retention

\section{Introduction}

The shortage of nurses internationally is a concern for most areas of practice. In Canada, it is estimated that there will be a deficit of 60,000 full-time Registered Nurse (RN) positions by $2022 .{ }^{[1]}$ High job demands, ${ }^{[2]}$ low work control, ${ }^{[2]}$ increased emotional demands in the work environment, ${ }^{[3]}$ work hours ${ }^{[4]}$ work-family conflicts, ${ }^{[4]}$ lack of a supportive team environment, ${ }^{[5]}$ poor collegial relationships with physicians ${ }^{[6]}$ not being recognized and rewarded for job performance, ${ }^{[7]}$ and lack of leadership visibility ${ }^{[7]}$ have all been identified as factors linked to nurses' intent to leave their positions. The impact of not having enough nurses can be felt on many different levels, but most importantly in the delivery of safe, quality care. Several studies have demonstrated the relationship between nursing staff levels and negative patient outcomes within healthcare settings, including

*Correspondence: Barb Pizzingrilli; Email: barb.pizzingrilli@niagarahealth.on.ca; Address: Mental Health and Addictions Program, Niagara Health System, St Catharines, Canada. 
falls, ${ }^{[8-10]}$ medication errors, ${ }^{[8,10]}$ infections,${ }^{[9,11]}$ and mortality rates. ${ }^{[12,13]}$

Many countries have directed energies at increasing the number of new graduate RNs as a strategy to address ongoing shortages. Given the emphasis on this valuable resource, there has been extensive research conducted to examine and understand the perspectives of new RNs entering the workforce and the challenges that they face particularly in the first year of practice when they are potentially most vulnerable. ${ }^{[14-21]}$ The need to understand the perspectives of new RNs is imperative especially given that $53 \%$ of new graduates will change positions within their first year of employment. ${ }^{[22]}$

Bowles and Candela, ${ }^{[14]}$ in their survey of 352 new RN graduates, examined perceptions of first job experience. The new RNs identified concerns related to patient care and specifically that work was very stressful, that they often had to stay at the end of their shift to complete assigned duties, staffing levels were inadequate, they had minimal time to spend with their patients, and were often floated to other areas where they did not feel prepared to perform the work required. The authors asked survey respondents to provide the reason for leaving their first job and $26 \%$ cited patient care related factors as being the main reason. Concerns about the acute nature of the patients they care for, staffing levels, and an overall perception of unsafe patient care were identified as factors influencing the decision to leave the first work experience.

Cylke ${ }^{[16]}$ conducted a needs assessment to provide nursing employers with the tools needed to improve new nurse graduate orientation programs. Eighty-eight new graduate nurses participated in completion of the Casey-Fink Graduate Nurse Experience Survey that was used to collect respondent answers. Cylke found that while $86 \%$ of the new nurses were excited and challenged by their work, over $54 \%$ found that the workload, including organization, prioritization, and patient acuity, was an issue. Additionally, lack of confidence, fear, orientation issues, and role expectations were also highlighted by respondents as areas of concern during the period of transition into their new nursing positions. In terms of confidence, the new nurses had difficulty communicating with patients and families, were uncomfortable delegating to other healthcare staff, and struggled with critical thinking skills.

Dyess and Sherman ${ }^{[17]}$ conducted focus groups with 81 new graduate RNs who had less than 12 months of practice experience. The authors identified that the RNs felt both confident and fearful as they transitioned into new and unknown patient situations. Even though the new graduates were working as members of the health team, they felt professionally isolated when attempting to work through new experiences and learning. This can be particularly problematic as they are expected to deal with potentially complex patient

Published by Sciedu Press related situations often within a short period of time. The authors also found that participant experiences were further confounded by receipt of different and often contradictory information from staff and often inaccessible policies and procedures. The inexperienced RNs, in contrast to their more experienced counterparts, may additionally be less familiar with standards of practice and available resources that will assist in problem solving complex clinical situations. ${ }^{\text {[23] }}$

Issues of violence in the workplace can be particularly overwhelming for new nurses who may lack the knowledge and confidence to address conflict with their colleagues. ${ }^{[24]}$ Tension and conflict can arise from multi-generational nurses coming together at different points in their career, with divergent foundational values, beliefs and philosophies. According to Vessey, DeMarco, and DiFazio ${ }^{[25]}$ violence includes any "offensive, abusive, intimidating, or insulting behaviours that cause psychological and/or physical distress to the recipient"(p. 136). Violence is typically problematic to identify as behaviours can be subtle in the workplace and as a result the victim often has difficulty in seeking assistance to remedy the situation. ${ }^{[26]}$ For new nurses who are not familiar with workplace supports and resources to assist in addressing issues of violence, this can be even more of a challenge.

Simons $^{[27]}$ surveyed 398 new nurses with less than three years' experience as part of a larger study examining bullying behaviour among nurses. The most frequently identified bullying behaviours, that occurred on both a weekly and daily basis, included someone withholding information that could impact personal performance, being humiliated, being ordered to work below competence level, being the subject of gossip and rumours, being ignored or excluded, having personal opinions and views ignored, being given tasks with unreasonable or impossible timelines, and an unmanageable workload. The author found that nurses' intent to leave their jobs increased as workplace bullying and exposure to violence increased.

Budin, Brewer, Chao, and Kovner ${ }^{[28]}$ surveyed 1407 early career RNs to examine the relationship between verbal abuse behaviours and factors such as demographics, work environment, and work attitudes. The authors found that higher levels of abuse were significantly related to lower levels of autonomy, supervisory support, mentor support, workgroup cohesion, promotional opportunities, and intent to stay than those who were not exposed to verbal abuse from their nursing colleagues. For early career nurses who reported moderate to high levels of verbal abuse, $29.6 \%$ indicated intent to leave their nursing positions within the next 12 months and $42.3 \%$ planned to leave within 1-3 years. Despite exposure to moderate to high levels of verbal abuse at the hands of their nursing colleagues, $77.5 \%$ of new nurses did not identify a plan to leave their current position within the next three years. The fact that new nurses remain in violent environments, further supports that repeated expo- 
sure to conflict leads to a post-traumatic stress response in the victims, ${ }^{[26]}$ undermines self-confidence, contributes to feelings of humiliation, and leaves victims feeling vulnerable. $^{[25]}$

For RNs new to mental health, many will experience the same issues affecting new graduates across all practice settings. However, they also have to contend with choosing a practice environment that has been identified as less desirable to new graduates compared to other clinical areas. ${ }^{[29,30]}$ Several enduring myths have also been prevalent over the years that have deterred nurses from considering this area of specialty practice. Mental health has been inaccurately viewed as a destination for late career nurses who transition from more clinically intense areas to seek out a lesser workload. Additionally, mental health is seen as the clinical area in which global nursing skills will be lost due to lack of opportunity to use them and staff new to this area may have concerns about their own safety because of perceived patient population risks. ${ }^{[30]}$ Furthermore, lack of exposure to mental health placements can impact the motivation and readiness of new graduates to enter this field ${ }^{[31,32]}$ and limit the ability of new nurses considering this area of practice to understand and process the negative stereotypes surrounding mental health care. ${ }^{[33]}$ The odds of recruiting new nurses to mental health would seemingly appear to be stacked against healthcare organizations and, with an average annual mental health nursing turnover rate of $17.8 \%$ in Canada, ${ }^{[34]}$ retention is also problematic.

The use of a nursing residency program has been identified as an effective strategy in addressing issues of retention, ${ }^{[35-40]}$ new graduate confidence, ${ }^{[36,38,42-44]}$ and attainment of clinical skills and competencies. ${ }^{[41-46]}$ There is a paucity of research examining outcomes specific to mental health residency programs though some work has been done in this specialty area. The purpose of this paper is to detail the planning and implementation of a Mental Health Nursing Residency Program at the Niagara Health System for a cohort of staff new to mental health and addictions. The outcomes of the residency program will be discussed as well as challenges that will inform recommendations for future programs.

\subsection{Background}

In March 2013, a new Niagara Health System (NHS) hospital opened in St. Catharines, Ontario. The Mental Health and Addictions Program, prior to the new hospital, consisted of inpatient mental health beds, adult outpatient, and children's services at three hospital sites. With the new hospital, the inpatient beds from the three sites consolidated with creation of two acute inpatient units consisting of 44 beds. In addition to the inpatient beds, a number of new services were introduced within both the inpatient and outpatient programs. Planning for the new hospital occurred over several years and one of the key components was a comprehensive Human Resources strategy across all programs and services. While there were some areas of growth within other NHS programs, the Mental Health and Addictions Program had the greatest number of new services and expansion potential that had significant implications for recruitment and training.

The Mental Health and Addictions Program leadership team met on a weekly basis to review and discuss the new hospital operational readiness plan to ensure that timelines were met and that all facets of readiness were identified. In discussing staffing requirements for the new hospital, it was decided to begin recruitment early in 2012 in order to have staff trained and ready to move into positions when the new hospital opened. Recruitment efforts were initiated and ten new staff (see Table 1) were initially hired consisting of six new graduate Registered Nurses (RN), one new graduate Registered Practical Nurse (RPN), two RNs with less than one year experience and one RN who transferred from a medical unit and therefore was new to the area of mental health and addictions.

Table 1: Mental health nursing residency program participant demographics

\begin{tabular}{ll}
\hline Characteristics & Percentage (n = 10) \\
\hline Age & \\
$\geq 30$ & $30 \%(\mathrm{n}=3)$ \\
$<30$ & $70 \%(\mathrm{n}=7)$ \\
Gender & \\
Male & $20 \%(\mathrm{n}=2)$ \\
Female & $80 \%(\mathrm{n}=8)$ \\
Professional Designation & \\
RN & $90 \%(\mathrm{n}=9)$ \\
RPN & $10 \%(\mathrm{n}=1)$ \\
Education & \\
Diploma & $10 \%(\mathrm{n}=1)$ \\
Undergraduate & $90 \%(\mathrm{n}=9)$ \\
Other & $0 \%(\mathrm{n}=0)$ \\
Years Worked with People with Mental Illness & \\
0 Years & $70 \%(\mathrm{n}=7)$ \\
1 Year & $20 \%(\mathrm{n}=2)$ \\
2-4 Years & $10 \%(\mathrm{n}=1)$ \\
$5-9$ Years & $0 \%(\mathrm{n}=0)$ \\
$\geq 10$ Years & $0 \%(\mathrm{n}=0)$ \\
\hline
\end{tabular}

Historically, orientation for new staff coming into the NHS Mental Health and Addictions Program has consisted of a five day classroom-based experience with introduction of comprehensive theoretical content that was applied to preceptored shifts in the clinical area, which ranged on average from five to seven shifts. Hiring of new staff has been episodic within the Program resulting in many new staff not attending mental health orientation at all or sometimes several months after starting. Given the unique knowledge and skills required for mental health nursing practice the established orientation process may not meet the needs of all new staff in providing the foundational competencies to transition into independent practice. The use of a residency pro- 
gram was identified as a strategy that could provide a solid base of knowledge and skills for the group of ten new staff in readiness for the new hospital rather than using the established orientation program.

The Mental Health Nursing Residency Program ${ }^{[47]}$ was originally developed by eight collaborating organizations that came together as part of the Ontario Ministry of Health and Long-Term Care Nursing Health and Human Resources Planning Demonstration Sites initiative in 2007/2008. The partners were: Centre for Addiction and Mental Health, Mental Health Centre Penetanguishene, Providence Care, Mental Health Services Site (Kingston), Royal Ottawa Health Care Group, Ontario Shores Centre for Mental Health Sciences, Algonquin College, University of Ontario Institute of Technology, and University of Ottawa. The Program is based on the Canadian Standards for Psychiatric Mental Health Nursing ${ }^{[48]}$ and includes classroom based sessions totaling approximately 40 hours integrated with clinical activities that are related to the theoretical content introduced in class. The intent of the overall program is to provide specialty training that will ensure alignment of nursing practice with mental health standards and transition of the novice practitioner to the second stage of Benner's clinical competence model, which is Advanced Beginner. ${ }^{\text {[9] }}$

Transitional funding related to the new hospital was available to support the 12-week residency program duration. The residency program plan was presented and approved by the Mental Health and Addictions Program Steering Committee and planning was initiated.

\subsection{Program planning}

The planning stage initially began with a telephone consultation with a Nursing Practice Consultant ${ }^{[50]}$ at St. Joseph's Healthcare Hamilton. Recommendations were made by the Nursing Practice Consultant based on St. Joseph's experience with the Mental Health Nursing Residency Program. She identified the need for consistent mentors for new staff and strong nursing leadership to ensure that the program stays on track and that any barriers are addressed in a timely manner. St. Joseph's Healthcare Hamilton had updated the original Mental Health Nursing Residency Program content and provided this to the Niagara Health System to use as the basis for refinement of its own program.

A Nursing Residency Program Steering Committee was developed consisting of the Mental Health and Addictions Program Director, Manager of Program Development, Clinical Manager, Educator, and a front-line RN. As an ad hoc member, the NHS Chief Nursing Executive did not attend all meetings but was updated on the Residency Program progress. The initial meeting of the Steering Committee was June 7, 2012 and it was identified immediately that meeting weekly would be important especially given the tight timelines for beginning the Program in July. Once the Residency

Published by Sciedu Press
Program was underway, the Steering Committee continued to meet though the frequency of the meetings decreased from the original weekly commitment as there were minimal issues that arose during the 12 weeks.

The Mental Health and Addictions Program Educator updated the Mental Health Nursing Residency Program content provided by St. Joseph's Healthcare Hamilton to reflect Niagara specific information. The Program Educator included regularly scheduled clinical activities with the more commonly used mental health and addictions community programs to increase new staff awareness of resources and to begin building relationships with community agencies. The Program Educator also worked closely with the Clinical Managers in identifying mentors for the Residency Program. Many of the chosen mentors had previously attended mentor training workshops and were considered to be experienced nursing staff in their clinical areas.

An e-mail was sent by the Program Educator inviting all Residency Program participants to attend a "launch day," which was scheduled for July 19, 2012. In addition to the residents and the Program Educator, the NHS Chief Executive Officer, Chief Nursing Officer, and the Mental Health and Addictions Program Leadership Team, consisting of the Vice President, Regional Chief, Director, Clinical Managers, and Manager of Program Development, attended the launch celebration.

\section{Methods}

The Residency Program was evaluated using a pre-post design. The specific outcomes that were evaluated include: (i) knowledge acquisition related to mental health and addictions content; (ii) confidence levels; (iii) attitudes about mental health recovery; and (iv) retention rates of the Residency Program participants.

\subsection{Sample}

A convenience sample $(n=10)$ was used consisting of nine Registered Nurses and one Registered Practical Nurse who participated in the 12-week Mental Health Nursing Residency Program at the Niagara Health System in 2012. Approval was obtained from the Niagara Health System Research Ethics Board.

\subsection{Instruments}

The knowledge test administered to the Residency Program participants to evaluate knowledge acquisition was constructed by the Mental Health and Addictions Program Educator. The 45-question test was derived from the Residency Program content including areas such as the Mental Health Act, trauma, violence risk, recovery, addictions, psychotropic medications, and emergency response.

Confidence levels were measured using the Mental Health 
Nursing Clinical Confidence Scale (MHNCCS), ${ }^{[51]}$ which consists of 20 questions that assess different elements of confidence within mental health settings. The items on the MHNCCS are scored using a 4-point Likert scale where 1 is not all confident and 4 is completely confident.

The 16-item Recovery Attitudes Questionnaire was used to determine beliefs and attitudes about recovery within the context of mental health and addictions issues. ${ }^{[52]}$ The 16 questions are answered using a 5-point Likert scale where 1 is strongly disagree and 5 is strongly agree.

\subsection{Data collection procedures}

Quantitative data were collected by the Mental Health and Addictions Program Educator at the beginning of the Mental Health Nursing Residency Program and on the last day using the same instruments. The selected instruments measured knowledge, confidence levels, and recovery attitudes. Data were de-identified prior to statistical analysis.

\subsection{Data analysis}

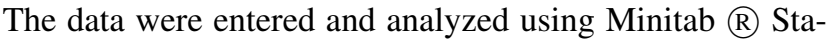
tistical Software ${ }^{[53]}$ for eight of the ten participants as two people did not complete the full 12-week Residency Program. The pre-post knowledge and confidence scores were compared and analyzed using paired t-tests. Statistical significance was recognized for $P$-values of $<.05$. Descriptive statistics were used to describe the sample demographics, participant attitudes related to mental health recovery, and retention.

\section{Results}

\subsection{Knowledge}

The mean, standard deviation (SD), $t$-test result, and level of significance for knowledge scores at the start (pre-test) and end (post-test) of the Mental Health Nursing Residency Program are shown in Table 2. There was a statistically significant increase in the knowledge scores between the pre-test and the post-test. These results support that the Residency Program does have an impact on knowledge acquisition in key content areas required for mental health nursing practice.

Table 2: Pre-post knowledge test scores $(\mathrm{n}=8)$

\begin{tabular}{llllll}
\hline & $\begin{array}{l}\text { Mean } \\
\text { (Pre) }\end{array}$ & $\begin{array}{l}\text { Standard } \\
\text { Deviation }\end{array}$ & $\begin{array}{l}\text { Mean } \\
\text { (Post) }\end{array}$ & $\begin{array}{l}\text { Standard } \\
\text { Deviation }\end{array}$ & $\begin{array}{l}\text { Paired } \\
\text { T-Test }\end{array}$ \\
\hline Knowledge Scores & 31.25 & 4.98 & 38.13 & 2.70 & $-5.58^{*}$ \\
\hline${ }^{*} P<.05$ & & & & &
\end{tabular}

\subsection{Confidence levels}

The mean, standard deviation (SD), $t$-test result, and level of significance for confidence scores at the start (pre-test) and end (post-test) of the Mental Health Nursing Residency
Program are shown in Table 3. All participants had an improvement in their confidence ratings over the course of the 12 weeks with the exception of two individuals, with one having exactly the same score pre and post scores and another who had a 10-point decrease in the confidence score.

A paired $t$-test was used to test the mean difference between the pre and post confidences scores for the eight Residency Program participants. Analysis was completed for each individual scale question. There was an improvement in the mean scores for all 20 items between the pre and post period. The residents showed statistically significant improvement in the areas of communication (pre-mean $=2.75, S D$ $=0.71$; post-mean $3.63, S D=0.52 ; P=.021$ ), counseling skills (pre-mean $=2.25, S D=0.71$; post-mean 3.50, $S D$ $=0.54 ; P=.011$ ), establishing treatment goals for patients with mental illness (pre-mean $=2.63, S D=0.74$; post-mean $3.50, S D=0.54 ; P=.006$ ), knowledge of antipsychotic medications (pre-mean $=2.25, S D=0.71$; post-mean 3.25 , $S D=0.46 ; P=.007)$, knowledge of anti-anxiety medications (pre-mean $=2.50, S D=0.76$; post-mean 3.38, $S D=$ $0.52 ; P=.006$ ), knowledge of antidepressants (pre-mean = 2.63, $S D=0.74$; post-mean 3.25, $S D=0.46 ; P=.049$ ), knowledge of mood stabilizers (pre-mean $=2.50, S D=$ 0.76 ; post-mean $3.25, S D=0.46 ; P=.020$ ), conducting mental status examinations (pre-mean $=2.63, S D=0.52$; post-mean $3.63, S D=0.52 ; P=.007$ ) and completing psychosocial assessments (pre-mean $=2.25, S D=0.71$; postmean 3.25, $S D=0.46 ; P=.007)$.

\subsection{Recovery attitudes questionnaire}

The mean recovery attitude scores at the start (pre-test) and end (post-test) of the Mental Health Nursing Residency Program are shown in Table 4 . The mean scores were improved between the pre and post periods in 13 of the 16 recovery attitude items, or $81 \%$. These results suggest that the Residency Program does have an impact on recovery attitudes and participants recognize that the way in which individuals recover is unique and that hope, courage, faith, and support are important to the recovery process. Question 3 had no change between the pre and post scores, which indicates that the residents do not believe that an understanding of one's mental illness is helpful in recovery.

The only question that had a decrease in the mean recovery attitudes score between the start and end of the Residency Program was number 13, which asked participants about the influence of stigma for the recovery process. The results of this question can be used to inform the curriculum for future residency cohorts with potentially a greater focus on the topic of stigma, which has been identified as a significant barrier for individual recovery. ${ }^{[54]}$ Staff need to understand and appreciate the impact of stigmatizing attitudes, including their own, in order to support the recovery journey of individuals with mental health issues. 
Question 10 of the RAQ-16 is reverse coded and asks "People who recover from mental illness were not really mentally ill in the first place." The results for this question did not change between the beginning and end of the residency period. This potentially suggests that participants do not appreciate that recovery can occur within the context of serious and persistent mental health and/or addictions issues despite presentation of theoretical and consumer based recovery journey information during the Residency Program.

Table 3: Pre-post mental health nursing clinical confidence scale scores $(n=8)$

\begin{tabular}{|c|c|c|c|c|c|}
\hline Individual Scale Items & Mean (Pre) & $\begin{array}{l}\text { Standard } \\
\text { Deviation }\end{array}$ & $\begin{array}{l}\text { Mean } \\
\text { (Post) }\end{array}$ & $\begin{array}{l}\text { Standard } \\
\text { Deviation }\end{array}$ & $\begin{array}{l}\text { Paired } \\
\text { T-Test }\end{array}$ \\
\hline $\begin{array}{l}\text { 1. I am able to be empathetic with a range of persons with } \\
\text { mental illness. }\end{array}$ & 3.50 & 0.76 & 3.88 & 0.35 & -1.43 \\
\hline $\begin{array}{l}\text { 2. I can seek support from other members of the mental } \\
\text { health team. }\end{array}$ & 3.63 & 0.52 & 3.88 & 0.35 & -1.53 \\
\hline $\begin{array}{l}\text { 3. I am able to establish my own personal boundaries } \\
\text { when relating to persons with a mental illness. }\end{array}$ & 3.50 & 0.54 & 3.75 & 0.46 & -1.53 \\
\hline $\begin{array}{l}\text { 4. I can contribute patient-related mental health } \\
\text { information at a multidisciplinary meeting. }\end{array}$ & 2.88 & 0.84 & 3.13 & 0.99 & -0.61 \\
\hline $\begin{array}{l}\text { 5. I can communicate effectively with persons with a } \\
\text { mental health problem. }\end{array}$ & 2.75 & 0.71 & 3.63 & 0.52 & $-2.97 *$ \\
\hline $\begin{array}{l}\text { 6. I can fit with the nursing team on a mental health } \\
\text { clinical placement. }\end{array}$ & 3.38 & 0.52 & 3.63 & 0.74 & -0.68 \\
\hline $\begin{array}{l}\text { 7. I can provide information and education for patients } \\
\text { regarding their diagnosis. }\end{array}$ & 2.63 & 0.74 & 3.00 & 0.76 & -1.16 \\
\hline $\begin{array}{l}\text { 8. I am able to provide basic counseling for persons with } \\
\text { a mental illness. }\end{array}$ & 2.25 & 0.71 & 3.50 & 0.54 & $-3.42 *$ \\
\hline $\begin{array}{l}\text { 9. I can assist patients with a mental illness to clarify } \\
\text { treatment goals. }\end{array}$ & 2.63 & 0.74 & 3.50 & 0.54 & $-3.86^{*}$ \\
\hline $\begin{array}{l}\text { 10. I have a basic knowledge of antipsychotic } \\
\text { medications and their side effects. }\end{array}$ & 2.25 & 0.71 & 3.25 & 0.46 & $-3.74 *$ \\
\hline $\begin{array}{l}\text { 11. I can develop a nursing care plan on the basis of my } \\
\text { assessment. }\end{array}$ & 2.75 & 0.71 & 3.13 & 0.35 & -1.43 \\
\hline $\begin{array}{l}\text { 12. I have a basic knowledge of anti-anxiety medications } \\
\text { and their side effects. }\end{array}$ & 2.50 & 0.76 & 3.38 & 0.52 & $-3.86^{*}$ \\
\hline $\begin{array}{l}\text { 13. I have a basic knowledge of antidepressants and their } \\
\text { side effects. }\end{array}$ & 2.63 & 0.74 & 3.25 & 0.46 & $-2.38 *$ \\
\hline $\begin{array}{l}\text { 14. I have a basic knowledge of mood stabilizers and } \\
\text { their side effects. }\end{array}$ & 2.50 & 0.76 & 3.25 & 0.46 & $-3.00 *$ \\
\hline 15. I can conduct a mental status examination. & 2.63 & 0.52 & 3.63 & 0.52 & $-3.74 *$ \\
\hline 16. I can handle patients who are verbally aggressive. & 2.88 & 0.64 & 3.25 & 0.71 & -1.00 \\
\hline $\begin{array}{l}\text { 17. I can carry out a comprehensive psychosocial } \\
\text { assessment of patients. }\end{array}$ & 2.25 & 0.71 & 3.25 & 0.46 & $-3.74 *$ \\
\hline $\begin{array}{l}\text { 18. I am able to provide patient education regarding the } \\
\text { effects of medications. }\end{array}$ & 2.88 & 0.99 & 3.25 & 0.46 & -1.16 \\
\hline 19. I can handle patients who are physically aggressive. & 2.63 & 1.06 & 3.13 & 0.64 & -1.53 \\
\hline 20. I am able to assist patients to develop living skills. & 3.13 & 0.84 & 3.38 & 0.52 & -0.80 \\
\hline
\end{tabular}
$* P<.05$

\subsection{Retention}

Of the ten participants who took part in the Mental Health Nursing Residency Program, only five $(50 \%)$ are still with the Niagara Health System at the two year mark. Within the first year following completion of the Residency Program, one staff member relocated to another community to Published by Sciedu Press be closer to family $(10 \%)$, one $(10 \%)$ was unsuccessful in passing the Ontario registration exam, one (10\%) left to pursue other employment, and two (20\%) left for undisclosed reasons. The retention rate was lower than expected particularly within the context of significant resource commitment to actualize the Residency Program. 
Table 4: Recovery attitudes questionnaire scores $(n=8)$

\begin{tabular}{|c|c|c|}
\hline Individual Questionnaire Items & $\begin{array}{l}\text { Pre-Score } \\
\text { (Mean) }\end{array}$ & $\begin{array}{l}\text { Post-Score } \\
\text { (Mean) }\end{array}$ \\
\hline 1. People who are in recovery need the support of others. & 4.75 & 5 \\
\hline 2. Recovering from mental illness is possible no matter what you think may cause it. & 3.75 & 4.5 \\
\hline 3. A good understanding of one’s mental illness helps in recovery. & 4.75 & 4.75 \\
\hline 4. To recover requires faith. & 3.63 & 4.5 \\
\hline 5. Recovery can occur even if symptoms of mental illness are present. & 4.25 & 4.75 \\
\hline 6. People in recovery sometimes have setbacks. & 4.75 & 5 \\
\hline 7. People differ in the way they recover from a mental illness. & 4.5 & 4.88 \\
\hline 8. Recovering from mental illness can occur without help from mental health professionals. & 3.13 & 3.25 \\
\hline 9. All people with serious mental illness can strive for recovery. & 3.88 & 4.75 \\
\hline 10. People who recover from mental illness were never really ill in the first place. & 1.25 & 1.25 \\
\hline 11. The recovery process requires hope. & 4.25 & 5 \\
\hline 12. Recovery does not mean going back to the way things used to be. & 3.75 & 4 \\
\hline 13. Stigma associated with mental illness can slow the recovery process. & 4.88 & 4.63 \\
\hline 14. Recovering from the consequences of mental illness is sometimes more difficult than recovering. & 4 & 4.63 \\
\hline 15. The family may need to recover from the impact of a loved one's mental illness. & 4.63 & 4.88 \\
\hline 16. To recover requires courage. & 4.63 & 4.88 \\
\hline
\end{tabular}

\section{Discussion}

The Mental Health and Addictions Residency Program at Niagara Health System was successful in assisting novice practitioners, new to this specialty area of practice in attaining core knowledge, building confidence, and adopting recovery-oriented attitudes. The combination of classroom based theoretical content integrated with in-hospital clinical experiences and community based orientation time contributed to a solid foundation of knowledge and skills required for mental health and addictions nursing practice.

This program was innovative in that the experiences the participants had were not limited solely to their area of clinical focus. Instead, the curriculum was adapted to include significant exposure to community based programs that will enable staff to begin developing connections with these agencies and building an understanding of community services that can then be incorporated into care planning with clients.

The Mental Health Nursing Residency Program that was originally developed as part of the Ministry of Health and Long-Term Care Nursing Health and Human Resources Planning Demonstration Sites initiative in 2007/08 was specifically for Registered Nurses. At NHS, the Residency Program included a Registered Practical Nurse. While psychiatric and mental health nursing standards set by the Canadian Federation of Mental Health Nurses ${ }^{[48]}$ are for Registered Nurses, the core standard categories can be applied to the Registered Practical Nurse role as well within the context of identified scope of practice.
A 12-week Residency Program can be costly especially in light of healthcare funding constraints. However, as part of new hospital planning and with transitional funding opportunities, options for the use of a Residency Program for training of new staff should be considered. Investment in the orientation of new novice practitioners at the front-end of their hospital tenure will potentially build commitment and loyalty in a healthcare environment where staff shortages are present. While the retention rate for the Mental Health Nursing Residency Program cohort was lower than expected, previous research has identified that nursing turnover rates decline as residency program curriculum adjustments are made based on resident feedback ${ }^{[55]}$ and with the number of cohorts completed. ${ }^{[4,56]}$ It is anticipated that with revisions to the 12-week Residency Program and additional cohorts, the retention rate will increase but further research would need to be undertaken to verify these assumptions.

\section{Conclusion}

The results presented in this paper contribute to the mental health and addictions literature and demonstrate that a residency program can be an effective strategy to ensure that nurses new to the field of mental health and addictions have the competencies required for practice. In a healthcare environment in which nurses are a valuable commodity, any intervention that will support new staff in increasing knowledge, confidence, and attitudes should be explored by organizations. 


\section{References}

[1] Tomblin Murphy, G., MacKenzie, A., Alder, R., Birch, S., Kephart, G., O'Brien-Pallas, L. An applied simulation model for estimating the supply of and requirements for registered nurses based on population health needs. Policy Political Nursing Practice. 2009; 10(4): 240-251. PMID:20164064 http://dx .doi .org/10.1177 $/ 1527154409358777$

[2] Chiu, Y.L., Chung, R.G., Wu, C.S., Ho, C.H. The effects of job demands, control, and social support on hospital clinical nurses' intention to turn over. Applied Nursing Research. 2009; 22(4): 258 263. PMID:19875040 http://dx.doi.org/10.1016/j.apnr. 2008.02.006

[3] Li, J., Fu, H., Hu, Y., Shang, L., Wu, Y., Kristensen, T.S., et al. Psychosocial work environment and intention to leave the nursing profession: Results from the longitudinal Chinese NEXT study. Scandinavian Journal of Public Health. 2010; 38(1): 6980. PMID:21172773 http://dx.doi .org/10.1177/140349480 9354361

[4] Flinkman, M., Laine, M., Leino-Kilpi, H., Hasselhorn, H.M., Salanterä, S. Explaining young registered Finnish nurses' intention to leave the profession: A questionnaire survey. International Journal of Nursing Studies. 2008; 45(5): 727-739. PMID:17280674 http://dx.doi.org/10.1016/j.ijnurstu.2006.12.006

[5] Tei-Tominaga, M., Miki, A. A longitudinal study of factors associated with intentions to leave among newly graduated nurses in eight advanced treatment hospitals in Japan. Industrial Health. 2010; 48(3): 305-316. PMID:20562506 http://dx.doi.org/10.2486 /indhealth.48.305

[6] Lavoie-Tremblay, M., Paquet, M., Marchionni, C., Drevniok, U. Turnover intention among new nurses: A generational perspective. Journal for Nurses in Staff Development. 2011; 27(1): 3945. PMID:21263280 http://dx.doi .org/10.1097/NND. 0b013 e31819945c1

[7] Duffield, C.M., Roche, M.A., Blay, N., Stasa, H. Nursing unit managers, staff retention and the work environment. Journal of Clinical Nursing. 2011; 20(1-2): 23-33. PMID:21158986 http://dx.doi . org $/ 10.1111 / \mathrm{j} .1365-2702.2010 .03478 . \mathrm{x}$

[8] Bae, S.H., Mark, B., Fried, B. Impact of nursing unit turnover on patient outcomes in hospitals. Journal of Nursing Scholarship. 2010; 42(1): 40-49. PMID:20487185 http://dx.doi.org/10.1111/j $.1547-5069.2009 .01319 . x$

[9] Manojlovich, M., Sidani, S., Covell, C.L., Antonakos, C.L. Nurse dose: Linking staffing variables to adverse patient outcomes. Nursing Research. 2011; 60(4): 214-220. PMID:21691239 http://dx .doi.org/10.1097/NNR. 0b013e31822228dc

[10] Patrician, P.A., Loan, L., McCarthy, M., et al. The association of shift-level nurse staffing with adverse patient events. Journal of Nursing Administration. 2011; 41(2): 64-70. PMID:21266884 http://dx.doi.org/10.1097/NNA.0b013e31820594bf

[11] Cimiotti, J.P., Aiken, L.H., Sloane, D. M., Wu, E.S. Nurse staffing, burnout, and health care-associated infection. American Journal of Infection Control. 2012; 40(6): 486-490. PMID:22854376 http: //dx.doi.org/10.1016/j.ajic.2012.02.029

[12] Needleman, J., Buerhaus, P., Pankratz, S., Leibson, C.L., Stevens, S.R., Harris, M. Nurse staffing and inpatient hospital mortality. New England Journal of Medicine. 2011; 364: 1037-1045. PMID:21410372 http://dx.doi.org/10.1056/NEJMsa10010 25

[13] Twigg, D., Duffield, C., Bremner, A., Rapley, P., Finn, J. The impact of nursing hours per patient day (NHPPD) staffing method on patient outcomes: A retrospective analysis of patient and staffing data. International Journal of Nursing Studies. 2011; 48(5): 540548. PMID:20696429 http://dx.doi.org/10.1016/j.ijnur stu. 2010.07.013

[14] Bowles, C., Candela, L. First job experience of recent RN graduates. Improving the work environment. Nevada RN Information. 2005; 14(2): 16-19.
[15] Brewer, C.S., Kovner, C.T., Greene, W., Tukov-Shuser, M., Djukic, M. Predictors of actual turnover in a national sample of newly licensed registered nurses employed in hospitals. Journal of Advanced Nursing. 2011; 68(3): 521-538. PMID:22092452 http: //dx.doi.org/10.1111/j.1365-2648.2011.05753.x

[16] Cylke, K. Needs assessment: Blueprint for a nurse graduate orientation employer toolkit. Journal for Nurses in Staff Development. 2012; 28(2): 57-61. PMID:22449877 http://dx.doi.org/10. 1097/NND . 0b013e31824b4169

[17] Dyess, S. M., Sherman, R. O. The first year of practice: New graduate nurses' transition and learning needs. The Journal of Continuing Education in Nursing. 2009; 40(9): 403-410. PMID:19754027 http://dx.doi.org/10.3928/00220124-20090824-03

[18] Hickson, J. New nurses' perceptions of hostility and job satisfaction: Magnet versus non-magnet. Journal of Nursing Administration. 2013; 43(5): 293-301. PMID:23615372 http://dx.doi.o $\mathrm{rg} / 10.1097 / \mathrm{NNA} .0 \mathrm{~b} 013 \mathrm{e} 31828 \mathrm{eebc9}$

[19] Huntington, A., Gilmour, J., Tuckett, A., Neville, S., Wilson, D., Turner, C. Is anybody listening? A qualitative study of nurses' reflections on practice. Journal of Clinical Nursing. 2011; 20(910): 1413-1422. PMID:21414055 http://dx.doi.org/10.1111 $/ j .1365-2702.2010 .03602 . x$

[20] Karlowicz, K.A., Ternus, M.P. Issues influencing psychiatric nurse retention during the first year of employment: A case analysis. Journal of Nursing Management. 2009; 17(1): 49-58. PMID:19166522 http://dx.doi.org/10.1111/j.1365-2934.2008.00850.x

[21] Unruh, L.Y., Nooney, J. Newly licensed registered nurses' perceptions of job difficulties, demands and control: Individual and organizational predictors. Journal of Nursing Management. 2011; 19(5): 572-584. PMID:21749531 http://dx.doi.org/10.1111 /j.1365-2834.2011.01239.x

[22] Butler, K.M., Hardin-Pierce, M. Leadership strategies to enhance the transition from nursing student role to professional nurse. Nursing Leadership Forum. 2005; 9(3): 110-117. PMID:16206695

[23] Wiles, L.L., Simko, L.C., Schoessler, M. What do I do now? Clinical decision-making by new graduates. Journal for Nurses in Professional Development. 2013; 29(4): 167-172. PMID:23877286 http://dx.doi.org/10.1097/NND. 0b013e31829aeab3

[24] Mitchell, A., Ahmed, A., Szabo, C. Workplace violence among nurses, why are we still discussing this? Literature review. Journal of Nursing Education and Practice. 2014; 4(4): 147-150. http: $/ / \mathrm{dx}$.doi.org/10.5430/jnep.v4n4p147

[25] Vessey, J.A., DeMarco, R., DiFazio, R. Bullying, harassment, and horizontal violence in the nursing workforce: The state of the science. Annual Review of Nursing Research. 2010; 28(1): 133157. PMID:21639026 http://dx.doi .org/10 .1891/0739-668 6.28 .133

[26] Becher, J., Visovsky, C. Horizontal violence in nursing. MedSurg Nursing. 2012; 21(4): 210-214. PMID:22966523

[27] Simons, S. Workplace bullying experienced by Massachusetts registered nurses and the relationship to intention to leave the organization. Advances in Nursing Science. 2008; 31(2): E48E59. PMID:18497581 http://dx.doi.org/10.1097/01. ANS. $0000319571.37373 . d 7$

[28] Budin, W.C., Brewer, C.S., Chao, Y., Kovner, C. Verbal abuse from nursing colleagues and work environment of early career registered nurses. Journal of Nursing Scholarship. 2013; 45(3): 308-316. PMID:23627991

[29] Happell, B. Comprehensive nursing education in Victoria: Rhetoric or reality? Journal of Psychiatric and Mental Health Nursing. 2001; 8(6): 507-516. PMID:11842478 http://dx.doi.org/10.1046 /j.1365-2850.2001.00418.x

[30] Stevens, J., Brown, G., Graham, I. Career in mental health still an unlikely career choice for nursing graduates: A replicated longitudinal study. International Journal of Mental Health Nursing. 2013; 22(3): 213-220. PMID:22809315 http://dx.doi.org/10.1111 $/ j .1447-0349.2012 .00860 . x$

[31] Cleary, M., Happell, B. Promoting a sustainable mental health nursing workforce: An evaluation of a transition mental health nursing programme. International Journal of Mental Health Nursing. 2005; 
14(2): 109-116. PMID:15896258 http://dx.doi.org/10.1111 /j.1440-0979.2005.00367.x

[32] Holmes, C. The slow death of psychiatric nursing: What next? Journal of Psychiatric and Mental Health Nursing. 2006; 13(4): 401415. PMID:16867124 http://dx.doi.org/10.1111/j.1365-2 850.2006.00998.x

[33] Ross, C.A., Goldner, E.M. Stigma, negative attitudes and discrimination towards mental illness within the nursing profession: A review of the literature. Journal of Psychiatric and Mental Health Nursing. 2009; 16(6): 558-567. PMID:19594679 http://dx.doi .org/10.1111/j.1365-2850.2009.01399.x

[34] O'Brien-Pallas, L., Tomblin Murphy, G., Shamian, J. Understanding the costs and outcomes of nurses' turnover in Canadian hospitals. Final report submitted to Canadian Institute of Health Research. 2008.

[35] Altier, M.E., Krsek, C.A. Effects of a 1-year residency program on job satisfaction and retention of new graduate nurses. Journal for Nurses in Staff Development. 2006; 22(2): 70-77. PMID:16603904 http://dx.doi.org/10.1097/00124645-200603000-00006

[36] Herdrich, B., Lindsay, A. Nurse residency programs: Redesigning the transition into practice. Journal for Nurses in Staff Development. 2006; 22(2): 55-62. PMID:16603901 http://dx.doi.org/10. 1097/00124645-200603000-00003

[37] Hillman, L. Foster, R.R. The impact of a nursing transitions programme on retention and cost savings. Journal of Nursing Management. 2011; 19(1): 50-56. PMID:21223405 http://dx.doi.org $/ 10.1111 / j .1365-2834.2010 .01187 . x$

[38] Holland, C. Moddeman, G.R. Transforming the journey for newly licensed registered nurses. Journal of Continuing Education in Nursing. 2012; 43(7): 330-336. PMID:22493982 http://dx. doi .org /10.3928/00220124-20120402-16

[39] Keller, J.L., Meekins, K., Summers, B.L. Pearls and pitfalls of a new graduate academic residency program. Journal of Nursing Administration. 2006; 36(12): 589-598. PMID:17164616 http: //dx.doi.org/10.1097/00005110-200612000-00010

[40] Rosenfeld, P., Smith, M.O., Iervolino, L., Bowar-Ferres, S. Nurse residency program: A 5-year evaluation from the participants' perspective. Journal of Nursing Administration. 2004; 34(4): 188194. PMID:15097214 http://dx.doi.org/10.1097/0000511 0-200404000-00006

[41] Beyea, S.C., von Reyn, L.K., Slattery, M.J. A nurse residency program for competency development using human patient simulation. Journal for Nurses in Staff Development. 2007; 23(2): 7782. PMID:17414857 http://dx.doi.org/10.1097/01.NND.00 00266613.16434 .05

[42] Lindsey, G., Kleiner, B. Nurse residency program: An effective tool for recruitment and retention. Journal of Healthcare Finance. 2005; 31(3): 25-32. PMID:16080412

[43] Ng, S., Kessler, L., Srivastava, R., et al. Growing practice specialists in mental health: Addressing stigma and recruitment with a nursing residency program. Nursing Leadership. 2010; 23: 101112. PMID:20463449 http://dx.doi.org/10.12927/cjnl.2 010.21750

[44] Olson-Sitki, K.., Wendler, M.C., Forbes, G. Evaluating the impact of a nurse residency program for newly graduated registered nurses. Journal for Nurses in Staff Development. 2012; 28(4): 156162. PMID:22821016 http://dx.doi.org/10.1097/NND.0b0 $13 \mathrm{e} 31825 \mathrm{dfb} 4 \mathrm{c}$

[45] Kowalski, S., Cross, C.L. Preliminary outcomes of a local residency programme for new graduate registered nurses. Journal of Nursing Management. 2010; 18(1): 96-104. PMID:20465735 http: //dx.doi.org/10.1111/j.1365-2834.2009.01056.x

[46] Poynton, M.R., Madden, C., Bowers, R., Keefe, M. Nurse residency program implementation: The Utah experience. Journal of Healthcare Management. 2007; 52(6): 385-396. PMID:18087979

[47] Health Force Ontario. Mental Health Nursing Residency Program. Available from: http://www. mhnursingresidency.com/

[48] Canadian Federation of Mental Health Nurses. Canadian Standards of Psychiatric-Mental Health Nursing. 3rd Edition. Toronto: Author.2006.

[49] Benner, P. From novice to expert: Excellence and power in clinical nursing practice. Menlo Park: Addison-Wesley. 1984.

[50] Cheryl Evans (Nursing Practice Consultant, St. Joseph's Healthcare Hamilton) in discussion with the authors, May 2012.

[51] Bell, A., Horsfall, J. Goodin, W. The Mental Health Nursing Clinical Confidence Scale: A tool for measuring undergraduate learning on mental health clinical placements. Australia New Zealand Journal of Mental Health Nursing. 1998; 7(4): 184-190. PMID:10095468

[52] Steffen, J.J., Borkin, J.R., Krzton, K., Wishnick, H., Wilder, K.E. Consumer, Family Member, Mental Health Professional, and Student Versions of the Recovery Attitudes Questionnaire. Cincinnati, $\mathrm{OH}$ : Hamilton County Recovery Initiative Research Team, University of Cincinatti. 1999.

[53] Minitab 17 Statistical Software. Computer software. State College, PA: Minitab, Inc. 2010.

[54] Link, B.G., Struening, E.L., Neese-Todd, S., Asmussen, S., Phelan, J.C. Stigma as a barrier to recovery: The consequences of stigma for the self-esteem of people with mental illnesses. Psychiatric Services. 2001; 52(12): 1621-1626. PMID:11726753 http: //dx.doi.org/10.1176/appi.ps.52.12.1621

[55] Goode, C.J., Lynn, M.R., Krsek, C., Bednash, G.D. Nurse residency programs: An essential requirement for nursing. Nursing Economics. 2009; 27(3): 142-147. PMID:19558074

[56] Ulrich, B., Krozek, C., Early, S., Ashlock, C.H., Africa, L.M., Carmen, M.L. Improving retention, confidence, and competence of new graduate nurses: Results from a 10-year longitudinal database. Nursing Economics. 2010; 28(6): 363-375. PMID:21291057 